\title{
Pengembangan Formula Gel Ekstrak Pegagan (Centella asiatica (L.) Urb ) sebagai Antijerawat
}

Setia Budi*, Mila Rahmawati

Fakultas Kesehatan, Universitas Sari Mulia, Banjarmasin

*Corresponding author: setiabuddi62@gmail.com

Submitted: 17 Juni 2019

Accepted: 21 September 2019

Published: 29 Februari 2020

\begin{abstract}
Background: Recently, the topical antiacne medicines have been circulating in the form of gels and creams, but there are still a few of them contain herbs, as an active ingredient or agent which potentially prevent and treat acne such as pegagan (Centella asiatica (L.) Urb) because of antibacterial activity. Objective: To develop a stable formulation of pegagan gel. Methods: Testing of pegagan formulation according to the evaluation requirements based on gel concentration of 7\%, $8 \%$, and $9 \%$ as well organoleptic testing, $p H$, and viscosity. Extract of pegagan was added to the formula at concentration of $2.5 \%$ and $5 \%$. Evaluation of the formula includes homogeneity, acidity test, viscosity and spread potency. Results: Average $\mathrm{pH}$ of the formula was 6.66. There was a slight difference of viscosity between First Formula and Second Formula. Both of First Formula and Second Formula showed homogeneity and dispersion capacity in accordance with the requirements. Conclusion: During 14 days of testing, Second Formula with 5\% extract concentration more stable than Second Formula with an extract concentration of $2.5 \%$.
\end{abstract}

Keywords: Centella asiatica, extract gel, gel formulation

\begin{abstract}
Abstrak
Pendahuluan: Saat ini obat topikal antijerawat telah banyak beredar dalam bentuk gel dan krim, tetapi masih sedikit antijerawat topikal yang megandung herbal, sebagai bahan aktif atau agen berpotensi dapat mencegah dan mengobati jerawat seperti pegagan (Centella asiatica (L.) Urb) dengan sifat anti bakterinya. Tujuan: Mengembangkan formulasi sediaan gel pegagan yang stabil. Metode: Pengujian Formulasi pegagan sesuai persyaratan evaluasi dengan basis gel konsentrasi 7\%, 8\%, 9\%, selanjutnya dilakukan evaluasi meliputi pengujian organoleptik, pH, dan viskositas. Formula ditambah ekstrak herba pegagan dengan konsentrasi 2,5\% dan 5\%. Uji evaluasi formula yang dilakukan meliputi pengamatan homogenitas, uji derajat keasaman, kekentalan dan daya sebar sediaan. Hasil: Rerata pH sediaan didapatkan 6,66. Formula 1 dan Formula 2 terdapat sedikit perbedaan viskositas. Formula 1 dan Formula 2 menunjukkan homogenitas dan daya sebar yang sudah sesuai persyaratan. Kesimpulan: Selama 14 hari, pengujian Formula 2 dengan konsentrasi ekstrak 5\% lebih stabil dibandingkan Formula 1 dengan konsentrasi ekstrak 2,5\%.
\end{abstract}

Kata kunci: Centella asiatica, ekstrak gel, formulasi gel

\section{PENDAHULUAN}

Salah satu permasalahan yang sering dijumpai pada kulit saat ini dikalangan remaja adalah gangguan jerawat. Peradangan Polisebasea merupakan penyakit kulit yang disebut juga sebagai jerawat terjadi akibat peradangan menahun yang ditandai dengan adanya komedo, benjolan besar atau benjolan kecil, nodus dan kista pada bagian kulit wajah. Penyebab lainnya yang sering adalah infeksi bakteri mendominasi terjadinya permasalahan jerawat selain karena flora normal pada bagian kulit, Propionibacterium acne dan Staphylococcus aureus merupakan bakteri yang umum menginfeksi jerawat atau pada bagian kulit, sehingga ditemukan terapi yang salah pada masyarakat dengan mengobatinya menggunakan agen-agen antibakteri seperti antiseptik dan antibiotik yang tentu 
penggunaannya harus sangat diperhatikan terkait efek samping dan resistensi. Penggunaan sediaan dalam bentuk herbal akan lebih mudah ditoleransi oleh bagian tubuh manusia karena efek sampingnya akan lebih rendah (Djajadisastra dkk., 2009).

Menurut Wasitaatmadja (1997), ada beberapa cara penanganan jerawat yang efektif salah satunya dengan sediaan topikal. Saat ini sediaan topikal antijerawat telah banyak beredar dalam bentuk sediaan gel dan krim. Sediaan antijerawat lebih baik diformulasikan dalam sediaan gel, karena memiliki kemampuan berdifusi yang baik pada bagian kulit sehingga efek topikal diperoleh setelah bahan aktif menembus membran semipermiabel kulit. Gel merupakan sediaan topikal yang menggunakan formulasi basis polar sehingga mudah diterima oleh bagian kulit dan daya difusi yang ditimbulkan lebih baik dari krim karena kemampuannya melewati membran kulit lebih efektif daripada sediaan krim (Sasanti dkk., 2012).

Dengan pertimbangan keunggulan gel dalam penggunaan topikal tersebut maka dilakukan penelitian dengan tujuan mengembangkan formula gel dengan bahan aktif ekstrak pegagan (Centella asiatica (L.) Urb) sebagai antijerawat. Menurut penelitian Adria (2009), tanaman ini mempunyai aktivitas antibakteri terhadap Propionibacterium acne dan Staphylococcus aureus.

Pegagan termasuk salah satu tanaman obat yang telah banyak dikenal masyarakat. Pegagan mengandung asiatikosida, asam asiatat, dan asam madekasat yang mampu memacu penyembuhan luka. Karena itu, tanaman ini dapat digunakan sebagai sumber bahan aktif pada perawatan kulit yang mulai kusam, berkerut, atau menunjukkan tanda-tanda penuaan yang tidak diinginkan (Primastuti, 2013).

Khasiat lain dari asiatikosida yang terkandung dalam pegagan juga bisa mempercepat dan memicu pertumbuhan kolagen pada bagian kulit, sehingga bisa memperbaiki dan membuat regenerasi kulit ketika terjadi kerusakan kulit akibat jerawat (Sikareepaisan dkk., 2008).

\section{BAHAN DAN METODE}

\section{Bahan}

Pembuatan sediaan gel menggunakan bahan ekstrak daun pegagan didapat dari Borobudur Extraction Centre dengan No Batch 056PN01.2 dan ratio 10:1, viskolam, gliserin, propilengglikol, dimethylol dimethyl hydantoin (DMDM hydantoin), trietilamina (TEA), dan air suling.
Alat

Pengunaan alat pada pengujian formulasi sediaan gel ini adalah Magnetic stirrer (Cimarec), timbangan (Memmert), pH meter (Lutron 207), viskometer (Brookfield DV II +Pro), serta alat-alat gelas yang digunakan dalam pembuatan sediaan farmasi.

\section{Metode}

\section{Formulasi basis gel}

Pembuatan basis gel untuk sediaan terdiri dari viskolam, propilenglikol, gliserin, TEA (gtt), DMDM hydantoin dan air suling, kompesisi basis gel dapat dilihat pada (Tabel 1). Pembuatan basis gel dilakukan dengan cara mencampurkan viskolam dan sebagian air terlebih dahulu menggunakan alat Magnetic stirrer, kemudian ditambahkan gliserin dan propilengglikol, dan DMDM hydantoin. Untuk mendapatkan sediaan gel dengan homogenitas yang baik maka dilakukan pengadukan dengan perlahan dan di tambahkan secara kontinyu. Untuk mendapatkan derajat keasaman yang diinginkan maka harus ditambahkan TEA secara perlahan sampai didapatkan derajat keasaman yang diinginkan.

Tabel 1. Formula basis gel

\begin{tabular}{lccc}
\hline \multirow{2}{*}{\multicolumn{1}{c}{ Bahan }} & \multicolumn{3}{c}{ Komposisi Formula $(\% \mathrm{~b} / \mathrm{v})$} \\
\cline { 2 - 4 } & $\mathrm{F} 1$ & $\mathrm{~F} 2$ & $\mathrm{~F} 3$ \\
\hline Viskolam & 7 & 8 & 9 \\
Propilenglikol & 10 & 10 & 10 \\
Gliserin & 5 & 5 & 5 \\
TEA (gtt) & 15 & 20 & 15 \\
DMDM Hydantoin & 0,6 & 0,6 & 0,6 \\
Aquadest & 100 & 100 & 100 \\
\hline
\end{tabular}

\section{Pembuatan sediaan gel pegagan}

Setelah didapatkan basis gel terbaik formula, gel dengan konsentrasi ekstrak 2,5\% dan 5\% (Tabel 2). Pembuatan sediaan gel dimulai dari melarutkan ekstrak dengan air suling, kemudian dilakukan dengan cara mencampurkan viskolam dan sebagian air terlebih dahulu menggunakan alat stirer, kemudian ditambah gliserin dan propilengglikol, dan ditambahkan $D M D M$ hydantoin. Ekstrak herba pegagan (Centella asiatica (L) urban) dan air suling sampai volume yang diinginkan dengan pengadukan perlahan secara kontinyu sampai membentuk gel yang homogen. Selanjutnya ditambah TEA tetes demi tetes sampai $\mathrm{pH}$ yang diinginkan. Gel disimpan dalam wadah tertutup pada suhu ruangan. 
Tabel 2. Formulasi basis gel ektrak pegagan

\begin{tabular}{lcc}
\hline \multirow{2}{*}{\multicolumn{1}{c}{ Bahan }} & \multicolumn{2}{c}{ Komposisi Formula (\% b/v) } \\
\cline { 2 - 3 } & $\mathrm{F} 1$ & $\mathrm{~F} 2$ \\
\hline Ekstrak Pegagan & 2,5 & 5 \\
Viskolam & 8 & 8 \\
Propilenglikol & 10 & 10 \\
Gliserin & 5 & 5 \\
TEA (gtt) & 25 & 30 \\
DMDM Hydantoin & 0,6 & 0,6 \\
Aquadest & 100 & 100 \\
\hline
\end{tabular}

\section{Prosedur evaluasi}

Prosedur evaluasi formulasi sediaan gel berguna untuk mengetahui kualitas awal sediaan gel setelah formulasi. Pengamatan dilakukan dari sejumlah aspek pengujian yaitu warna bau dan tekstur sediaan gel.

\section{Uji organoleptik}

Dilakukan pengujian organoleptik dengan mengamati bentuk fisik, bau, dan warna sediaan gel.

\section{Uji pH}

Pengujian derajat keasaman dilakukan dengan mengamati tingkat keasaman sediaan gel untuk menjamin sediaan gel tidak menyebabkan iritasi pada kulit. $\mathrm{pH}$ sediaan gel diukur dengan $\mathrm{pH}$ meter.

\section{Uji viskositas}

Uji viskositas dilakukan evaluasi kekentalan dan persentasi kesalahan pada sediaan gel. Spindle disesuaikan berdasarkan konsentrasi kekentalan sediaan. Digunakan spindle nomor 6 - 7, dan kecepatan yang disesuaikan. Spindle dicelupkan ke dalam sampel gel setelah kecepatan yang sudah disesuaikan. Nomor spindle disesuaikan diatur dan diamkan beberapa saat sampai nilai viskositas akan menunjukkan tingkat kekentalan dari basis gel.

\section{Uji homogenitas}

Pengujian kesamaan basis gel dilakukan dengan pengujian homogenitas untuk melihat pemerataan kandungan yang terdapat pada sediaan gel, sehingga zat aktif tersebar merata kedalam sediaan basis gel.

\section{Uji daya sebar}

Sebanyak 1 gram gel letakan di atas kaca berskala, dan bagian atasnya diberi kaca yang sama dengan beban yang berbeda-beda ( 25 gram, 50 gram, 75 gram dan 100 gram) dan dibiarkan dengan lama waktu kurang lebih 1 menit dan hitung penambahan luas daerah yang diberikan oleh sediaan. Suatu gel dikatakan baik apabila memiliki daya sebar yang luas ditandai dengan diameter yang besar (Voight, 1994). Menurut Garg dkk. (2002), Daya sebar sediaan gel yang baik antara $5-7 \mathrm{~cm}$.

\section{HASIL DAN PEMBAHASAN}

Pengujian formulasi pada penelitian ini dilakukan pada saat pembuatan basis sediaan gel topikal dengan konsentrasi basis viskolam 7\%, 8\% dan 9\%. Setelah dilakukan evaluasi basis yang meliputi organoleptik, $\mathrm{pH}$, serta viskositas. Didapatkan basis terbaik pada konsentrasi basis $8 \%$. Setelah itu dilakukan pembuatan sediaan gel topikal dengan bahan aktif ekstrak pegagan.

Pada formulasi ini dibandingan mutu sediaan dengan konsentrasi ekstrak 2,5\% dan 5\%. Setelah dilakukan praformulasi dipilih formula terbaik dengan konsentrasi zat aktif 5\% karena memiliki kekentalan yang memenuhi persyaratan dan $\mathrm{pH}$ yang tidak mengiritasi kulit. Dalam proses pembuatan, pengadukan tidak boleh terlalu cepat. Karena semakin cepat pengadukan, globul akan terbentuk semakin banyak yang akan mempengaruhi stabilitas sediaan (Nurdianti dkk., 2017).

\section{Hasil evaluasi basis gel}

Sediaan dengan basis konsentrasi $7 \%$ berwarna putih jernih, berbeda dengan basis $8 \%$ dan $9 \%$ yang berwarna bening dan didapatkan hasil dengan bau khas viskolam serta tekstur yang lembut dan mudah dioleskan.

\section{Pengukuran pH}

Berdasarkan hasil pengukuran $\mathrm{pH}$ diperoleh nilai $\mathrm{pH}$ untuk basis dengan konsentrasi $7 \%, 8 \%$, dan $9 \%$. Nilai $\mathrm{pH}$ tersebut sesuai karena masuk dalam rentang yang dianjurkan untuk sediaan topikal yaitu antara 4,5 - 8,0 (Dewi, 2010).

\section{Uji viskositas}

Pengukuran viskositas telah dilakukan pada basis dengan konsentrasi 7\%, 8\%, dan 9\% menggunakan viskometer Brookfield dengan spindle 4 dan kecepatan $4 \mathrm{rpm}$ pada ketiga formula. Berdasarkan hasil pengukuran viskositas diperoleh nilai viskositas untuk konsentrasi 7\%, 8\%, dan 9\%. Berdasarkan (Tabel 3) pada konsentrasi $8 \%$, menunjukkan viskositas yang memenuhi syarat kekentalan sediaan gel, rentang viskositas yang baik berada pada rentang $50-1000 \mathrm{dPa}$ (Nurahmanto et al., 2017).

Tabel 3. Pengujian viskositas pada formula basis gel

\begin{tabular}{clll}
\hline \multirow{2}{*}{$\begin{array}{c}\text { Kecepatan } \\
(\mathrm{rpm})\end{array}$} & \multicolumn{3}{c}{ Konsentrasi viskolam } \\
\cline { 2 - 4 } & $7 \%$ & $8 \%$ & $9 \%$ \\
\hline 100 & 5390 & 8060 & 14250 \\
\hline
\end{tabular}




\section{Hasil evaluasi gel}

Pengamatan organoleptis telah dilakukan pada hari ke-1, 3, 5, 7, 14 pada suhu ruang dengan suhu 25 $30^{\circ} \mathrm{C}$, diletakkan didalam lemari penyimpanan. Pengujian organoleptis dilakukan untuk menentukan sediaan gel apabila terjadi perubahan dalam bentuk fisik, warna, bau dan tekstur sediaan gel. Hasil pengamatan organoleptis pada (Tabel 4) menunjukkan bahwa Formula 1 memiliki warna hijau bening dan bertekstur lembut. Formula 2 memiliki warna hijau pekat dengan bau khas pegagan dan bertekstur lembut.

Tabel 4. Hasil pengujuan homogenitas dan organoleptis selama 14 hari

\begin{tabular}{|c|c|c|c|c|c|}
\hline Formula & H1 & H3 & H5 & H7 & H14 \\
\hline \multirow[t]{3}{*}{ Formula 1} & $\sqrt{ }$ & $\sqrt{ }$ & $\sqrt{ }$ & $\sqrt{ }$ & $\sqrt{ }$ \\
\hline & $\sqrt{ }$ & $\sqrt{ }$ & $\sqrt{ }$ & $\sqrt{ }$ & $\sqrt{ }$ \\
\hline & $\sqrt{ }$ & $\sqrt{ }$ & $\sqrt{ }$ & $\sqrt{ }$ & $\sqrt{ }$ \\
\hline Organoleptis & \multicolumn{5}{|c|}{$\begin{array}{c}\text { warna hijau bening dan } \\
\text { bertekstur lembut }\end{array}$} \\
\hline \multirow[t]{3}{*}{ Formula 2} & $\sqrt{ }$ & $\sqrt{ }$ & $\sqrt{ }$ & $\sqrt{ }$ & $\sqrt{ }$ \\
\hline & $\sqrt{ }$ & $\sqrt{ }$ & $\sqrt{ }$ & $\sqrt{ }$ & $\sqrt{ }$ \\
\hline & $\sqrt{ }$ & $\sqrt{ }$ & $\sqrt{ }$ & $\sqrt{ }$ & $\sqrt{ }$ \\
\hline Organoleptis & \multicolumn{5}{|c|}{$\begin{array}{c}\text { warna hijau pekat dengan } \\
\text { bau khas pegagan dan } \\
\text { bertekstur lembut }\end{array}$} \\
\hline
\end{tabular}

Keterangan: H!: Hari ke 1; H3: Hari ke 3; H5: Hari ke 5, H7: Hari ke 7; H14: Hari ke 14. ( $\sqrt{ }$ : Tidak terdapat partikel kasar). (*: Terdapat partikel kasar)

\section{Pengukuran pH}

Pengukuran $\mathrm{pH}$ dilakukan pada hari ke-1, 3, 5, 7, dan 14 pada suhu ruang. Pengukuran $\mathrm{pH}$ dilakukan dengan menggunakan $\mathrm{pH}$ meter sebanyak tiga kali pada masing-masing formula. Untuk melihat sediaan tidak mengiritasi kulit maka dilakukan pengujian derajat keasaman dengan alat $\mathrm{pH}$ meter pada kulit sesuai (Tabel 5). Semua sediaan topikal yang digunakan pada bagian kulit maka harus disesuaikan dengan derajat keasaman yang ada pada bagian organ yang akan mengalami kontak langsung dengan sediaan, baik topikal maupun transdermal tidak boleh terlalu asam karena akan mengiritasi dan tidak boleh terlalu basa karena akan menyebabkan kulit bersisik (Fauzy, 2012).

Tabel 5. Hasil pengujian $\mathrm{pH}$ formula basis gel

\begin{tabular}{llll}
\hline \multirow{2}{*}{$\mathrm{pH}$} & \multicolumn{3}{c}{ Konsentrasi } \\
\cline { 2 - 4 } & $7 \%$ & $8 \%$ & $9 \%$ \\
\cline { 2 - 4 } & 6,62 & 6,82 & 6,82 \\
\hline
\end{tabular}

Berdasarkan hasil pengukuran yang dilakukan dari hari ke 1 sampai hari ke $14 \mathrm{pH}$ diperoleh dengan nilai pH untuk F1 dan F2. Nilai pH tersebut sesuai karena pada hari pertama sampai hari ke 14 pengujian rata-rata $\mathrm{pH}$ yang diperoleh pada pengujian adalah 6,66 sudah sesuai (Tabel 6) dan masuk dalam rentang yang dianjurkan untuk sediaan topikal yaitu antara 4,5 - 8,0 (Dewi, 2010).

Tabel 6. Pengujian pH selama 14 hari

\begin{tabular}{|c|c|c|c|c|c|c|}
\hline Formula & & H1 & $\mathrm{H} 3$ & H5 & $\mathrm{H7}$ & H14 \\
\hline \multirow[t]{3}{*}{ Formula $1(2,5 \%)$} & R1 & 6,70 & 6,65 & 7,08 & 6,50 & 7,02 \\
\hline & $\mathrm{R} 2$ & 6,63 & 6,61 & 7,04 & 6,73 & 7,13 \\
\hline & R3 & 6,65 & 6,63 & 7,12 & 6,43 & 7,16 \\
\hline Rata-rata \pm SD & & $6,66 \pm 0,36$ & $6,63 \pm 0,20$ & $7,08 \pm 0,40$ & $6,55 \pm 1,56$ & $7,10 \pm 0,73$ \\
\hline \multirow[t]{3}{*}{ Formula $2(5 \%)$} & $\mathrm{R} 1$ & 7,79 & 7,76 & 7,70 & 7,58 & 6,88 \\
\hline & $\mathrm{R} 2$ & 7,77 & 7,74 & 7,68 & 7,11 & 6,73 \\
\hline & R3 & 7,78 & 7,73 & 7,66 & 7,08 & 6,82 \\
\hline Rata-rata \pm SD & & $7,78 \pm 0,10$ & $7,74 \pm 0,15$ & $7,68 \pm 0,20$ & $7,25 \pm 2,80$ & $6,81 \pm 0,75$ \\
\hline
\end{tabular}

Keterangan H1: Hari ke 1, H3: Hari ke 3, H5: Hari ke 5; H7: Hari ke 7, H14: Hari ke 14

R1: Replikasi 1, R2: Replikasi 2, R3: Replikasi 3

\section{Pengukuran viskositas}

Pada hari ke-1, 7 dan 14 dilakukan pengukuran viskositas. Pengukuran viskositas dilakukan pada menggunakan alat viskometer Brookfield dengan spindle 4, 6, dan 7 pada kecepatan 4 dan 50 rpm pada kedua formula sebanyak tiga kali pada masing-masing formula. Berdasarkan hasil pengukuran viskositas diperoleh nilai viskositas untuk F1 dan F2 pada hari ke-1, 7 dan 14. Berdasarkan penelitian pada F1 dan F2, menunjukkan bahwa terdapat perbedaan viskositas pada F1 dan F2 selama masa penyimpanan 14 hari. Pada pengujian F1 dari hari ke-1 hingga hari ke-7. pengujian ini bertujuan agar gel mudah dikeluarkan dari tube dan mudah dioleskan, dimana konsistensi berkaitan dengan daya alir gel.

\section{Uji homogenitas}

Menurut Ditjen POM (2000), pengujian homogenitas atau keseragamaan sediaan ini dilakukan untuk mengetahui kondisi homogenitas sediaan gel. Homogenitas ditunjukkan dengan tidak adanya tekstur 
kasar dari gel dengan adanya butiran-butiran kasar. Berdasarkan hasil uji homogenitas menunjukkan bahwa Formula 1 dan Formula 2 memiliki homogenitas yang baik.

\section{Uji daya sebar}

Berdasarkan hasil pemerataan atau daya penyebaran gel saat diaplikasikan pada kulit. menunjukkan bahwa hasil dari pengujian sediaan gel sudah sesuai dengan teoritis (Grag dkk., 2002) daya sebar yang baik yaitu $5-7 \mathrm{~cm}$. Berdasarkan hasil uji daya sebar dari kedua formula sesuai dengan literatur yaitu masuk dalam rentang yang dianjurkan $(5-7 \mathrm{~cm})$. Dapat dikatakan sediaan gel memiliki daya sebar yang baik.

\section{KESIMPULAN}

Dari kedua pengembangan formulasi gel ekstrak daun pegagan (Centella asiatica (L.) Urb.) diperoleh Formula 2 dengan konsentrasi ekstrak 5\% lebih stabil dibandingkan dengan Formulasi 1 dengan konsentrasi ekstrak 2,5\%.

\section{DAFTAR PUSTAKA}

Adria, G. (2009). Uji Aktivitas Krim Ekstrak Etanol Pegagan (Centella asiatica (L) Urb) terhadap Bakteri Penyebab Jerawat. Skripsi; Fakultas Farmasi Universitas Andalas, Padang.

Dewi, R. K. (2010). Optimasi Formulasi Mikroemulsi Sediaan Hormon Testosteron Undekanoat. Skripsi; Fakultas Kedokteran dan Ilmu Kesehatan Universitas Islam Negeri Syarif Hidayatullah, Jakarta.

Ditjen POM. (2000). Parameter Standar Umum Ekstrak Tumbuhan Obat. Jakarta: DepKes RI.

Djajadisastra, J., Mun'im, A. \& Dessy, N. P. (2009). Formulasi Gel Topikal dari Ekstrak Nerii Folium dalam Sediaam Anti Jerawat. Jurnal Farmasi Indonesia; 4; 210-216.

Fauzy, A. (2012). Pengaruh Konsentrasi Minyak Ikan terhadap Penetrasi Kurkumin dalam Sediaan Mikroemulsi Gel.Skripsi; Fakultas Matematika dan Ilmu pengetahuan Alam Universitas Indonesia.

Garg, A. D., Aggarwal, S. G. \& Sigla, A. K. (2002). Spreading of Semisolid Formulation. USA: Pharmaceutical Technology.

Kementrian Kesehatan Republik Indonesia, (2014), Farmakope Indonesia (edisi V). Jakarta: Kementrian Kesehatan RI.

Nurahmanto D., Mahrifah I. R. N. \& Rosyidi V. A. (2017). Formulasi Sediaan Gel Dispersi Padat Ibuprofen: Studi Geling Angent dan Senyawa Peningka. Ilmiah Manuntung; 3; 96-105.

Nurdianti, L., Azzahra, S. F. \& Aji, N. (2017). Pengembangan Formulasi Sediaan Gel Rambut Antiketombe Ekstrak Daun Pandan Wangi (Pandanus amaryllifolius Roxb.) dengan Menggunakan Viscolam sebagai Gelling Agent dan Uji Aktivitasnya terhadap Jamur Pityrosporum ovale. Jurnal Kesehatan Bakti Tunas Husada; 17; 456-467.

Primastuti, R. F. (2013). Antioxidant and Cytotoxic Activities of Centella asiatica L. Leaves and Extract of Green Coffee Beans in a Cream Preparation for Grade 1-3 Cellulite and Slimming. Makara Journal Sains; 17; 1-5.

Sasanti, T. J. Wibowo, M. S., Fidrianny, I. \& Caroline, S. (2012). Formulasi Gel Ekstrak Air Teh Hijau dan Penentuan Aktivitas Antibakterinya terhadap Propionibacterium acne. Skripsi: School of Pharmacy ITB.

Sikareepaisan, P., Suksamrarn, A. \& Supaphol, P. (2008). Electrospun Gelatin Fiber Mats Containing A Herbal Centella asiatica Extract and Release Characteristic of Asiaticoside. Nanotechnology; 19; 1-10.

Voight, R. (1994). Buku Pelajaran Teknologi Farmasi (Edisi V). Yogyakarta: Gadjah Mada University Press.

Wasitaatmadja, S. (1997). Penuntun Ilmu Kosmetik. Jakarta: Universitas Indonesia Press. 